\title{
Influence of Emotional Interaction on Learners' Knowledge Construction in Online Collaboration Mode
}

\author{
https://doi.org/10.3991/ijet.v17i02.28539 \\ Liqin Wen \\ Zhengzhou University of Light Industry, Zhengzhou, China \\ 2009055@zzuli.edu.cn
}

\begin{abstract}
With the development of mobile Internet and $5 \mathrm{~g}$ communication technology, online learning has become an important channel for different people to accumulate knowledge. Autonomous learning often ignores learners' emotional interaction, while online collaborative learning mainly depends on learners' cooperation and communication. Taking the undergraduates of a 211 university in Beijing as the research object, this study compiled a questionnaire on the impact of emotional interaction on learners' knowledge construction under the online collaboration mode, and demonstrated the intermediary role of emotional interaction in learners' online collaborative learning in knowledge construction. The empirical results show that the designed questionnaire is effective $\alpha$ the coefficient is 0.891 , greater than 0.8 . Therefore, the questionnaire has good reliability. The kmo value is 0.876 and the corresponding $\mathrm{p}$ value is 0 . Therefore, this questionnaire has good validity. Emotional response and expression significantly promote the establishment of learners' knowledge construction. Online collaboration plays a complete intermediary role in the positive promotion of emotional interaction on learners' knowledge construction. The results of this study are of great reference value to the establishment of an Internet plus based learning environment model based on the interaction and cooperation of web-based learners.
\end{abstract}

Keywords—online collaboration, emotion, learners, knowledge construction, mesomeric effect

\section{Introduction}

The combination of communication and information technologies such as artificial intelligence has caused great changes in educational methods. Traditional learning is based on classroom learning, which mainly adopts the teaching mode of "lectureacceptance." Teachers play a leading role, while students stay at the stage of passive acceptance. In this mode, the problems of insufficient communication and mutual learning among learners and the lack of equality in communication between teachers and students promote the emergence of "cooperative learning." With the upgrading of educational theory and practice, an increasing theories support collaborative learning, which plays a more important role under the background of the widespread existence 
of online education platforms. Online collaborative learning can enable students to form groups, conduct learning activities, and facilitate emotional communication among students. Online collaborative learning means that teachers and students study together in a team of two or more people to achieve the common goal of online learning, which emphasizes the contribution of each learner to the online collaborative learning group as a whole. According to the related meaning of collaborative learning theory, the offline teaching activities are moved to the online learning platform by establishing the network information and multimedia technologies as the bottom foundation. This way realizes the integration of various learning activities. In particular, Internet technology provides a good hardware foundation for online learning. On such a good basis, collaborative learning can give full play to the improvement of different teaching modes and learning methods, and it plays an irreplaceable role in enhancing learners' self-learning ability, providing learning efficacy, and mastering creative skills and teamwork spirit. The construction and development of online learning space is the current trend of educational information application. The development of Internet technology and the rise of various learning platforms have helped the emergence of online learning space. The emergence of online collaborative learning space has changed the way for learners to acquire knowledge and the way of sharing knowledge.

Online learning has become more popular than before, but the lack of supervision makes the emotional management of learners become the focus of attention. Under the collaborative learning mode, the online learning platform is to make learners adopt more efficient learning methods by creating a better emotional atmosphere. Thus, learners' own emotions can adapt to the environment. Emotion is generated by learners' adaptation to the environment in the long-term learning process. If the emotional interaction is more sufficient, then learners can constantly improve their learning energy, show positive learning motivation, fully stimulate their learning motivation and interest, and extend to all links of online learning to realize the construction of their online learning knowledge. The online collaborative learning system can evaluate the individual basic level of individual learners, integrate online learning resources by means of visual and systematic evaluation, meet the reconstruction of learners' personal knowledge structure, improve learning efficiency, and complete knowledge construction.

\section{Theoretical basis and hypothesis}

\subsection{Theoretical basis}

Fredrickson, B.L. put forward the theory of expansion and construction of positive emotions on the basis of the analysis and summary of the existing research results of related emotional theories [1]. This theory focuses on the study of positive emotions, and it holds that positive emotions can help individuals expand their thinking space and complete more learning tasks in a shorter time. Emotion theory holds that negative emotions will limit the scope of individual cognition and behavior under normal 
circumstances. On the contrary, positive emotion can drive the body to break the conventional thinking limit, expand the attention range and perception range, and enhance cognitive flexibility and conversion within a certain range of mood dispersion. The theory of positive emotion expansion and construction also holds that positive emotion has revocation effect, which mainly deals with various physiological activation states caused by negative emotion, and makes the organism return to the baseline level. This revocation effect is beneficial for the organism to preserve its strength and resources in a general environment. Apart from revoking the physiological activation, it also relieves and eliminates the thinking narrowness and tension caused by negative emotions.

Knowledge construction theory emphasizes that learners, as the subject of knowledge cognition, interact with teachers. The cognitive learning environment is the specific questions raised by the learners themselves according to their interests and hobbies, and the learning of knowledge is realized through data learning, interaction between teachers and students, and communication among classmates. The deeper and wider processing of knowledge is completed with the help of teachers. As a result, learners are always in the process of actively exploring and self-solving knowledge learning difficulties. Accordingly, students are enabled to realize deep learning construction behavior. Constructivist learning theory also holds that learning is a long-term accumulation process, and learners can master knowledge better by reviewing, understanding, and applying the learned knowledge. The general online learning system only evaluates learners' learning effect by examining their test scores. However, learners' mastery of different knowledge points will constantly change with the advancement of the learning process given that students' mastery of each knowledge point changes according to its application. The finished test scores can only represent the situation mastered at that moment. Fully proving the knowledge construction of online learning more comprehensively is necessary.

\subsection{Hypothesis proposal}

According to the existing literature, emotional interaction mainly includes three categories: emotional response, emotional assessment, and emotional expression.

Among them, emotional response refers to the reaction process of teachers to students and students to teachers or classmates in the learning process, which can be understood as the attitude expression of concern, care, support, and approval between teachers and students or classmates. The existing literature supports the research conclusion that emotional response is important in helping teachers and students build trust and care and enhancing partners' care among students [2]. Among them, McPhail, $\mathrm{K}$ believed that the education of accounting students can be realized by solving the comprehensive ability of students' emotional intelligence and cultivating the emotional skills of accounting students by strengthening emotional management [3]. Litvack, A conducted an exploratory study on MSW graduates from two postgraduate social work programs by using qualitative research methods and analyzed students' emotional reactions to the field education experience [4]. Egan, K explored the influence of fairy tales' structure, opposite concepts, and emotional components 
on children's learning performance [5]. The research showed that teachers' emotional response is beneficial to children's perception of the essence of fairy tales. Madsen, $\mathrm{C}$. $\mathrm{K}$ found that a person needs a certain degree of awakening in the learning process to make emotional response [6]. Gfeller, $\mathrm{K}$ studied the influence of music and text on audience's emotional response and emotion [7]. The results showed that significant differences exist in emotional response under five experimental conditions, and significant differences exist in emotional response before and after the test. Bibby, $\mathrm{T}$ believed that mathematics is often a subject with strong emotions [8]. The results showed that strengthening the emotional response between primary school teachers and students will help students understand the essence of mathematics better. Kim, E.J. argued that emotional feedback is the basic element of providing performance training, and the experimental results showed that verbal feedback from evaluators significantly impacts learning emotional response and self-efficacy [9]. Mottet, T.P. used emotional response theory to explain the relationship between students' perception of teachers' immediate behavior and cognitive and emotional learning [10]. The results showed that emotional response can obviously provide students with selfreported emotion and cognitive learning level. Brooks, R explored the emotional reactions of British and Danish students to higher education [11], and the results showed that emotional reactions are very important in helping to understand the ways in which specific groups of students participate in education and the obstacles they often face. Horan, S.M. believed that teacher communication can stimulate students' emotional response, which is a better predictor of cognitive learning and state motivation [12]. Woody, R. H showed that teachers are always in the process of teaching classical music, and increasing emotional response is conducive to improving students' listening experience of music. Therefore, this study puts forward hypothesis H1 [13].

H1: Emotional response significantly positively promotes learners' knowledge construction.

Emotional assessment can stimulate online learners' willingness to share and analyze knowledge and promote their metacognitive awareness. Therefore, emotional assessment mainly promotes cognitive process. Randler, $\mathrm{C}$ analyzed the understanding of environmental protection actions of the third and fourth grade students, and the results showed that emotional assessment is an important factor affecting their participation in environmental protection actions [14]. Brandtstadter, J (1987) discussed the influence of perceptual control over personal development on emotional assessment in adulthood [15]. The results showed that personal subjective control will affect emotional assessment. Fox, $\mathrm{P}$ found that strengthening emotional assessment of students and obtaining students' true psychological thoughts can greatly promote most students' positive behaviors and academic achievements [16]. Merrell, K. W obtained that emotional evaluation, as an important prevention and intervention strategy in the learning process, is important to promote the mental health of school students [17]. Ioannou, A put forward a model of game-based learning design using interactive desktop [18]. The research results showed that this learning design method is beneficial to strengthen students' emotional assessment and promote students' academic performance. Gutiérrez-Moret, M mentioned that the emotional intelligence level of 
the students in the survey object is quite high, but some professional differences exist between the students' emotional assessment [19]. Kamps, D thought that teachers' intensified classroom intervention can improve the coefficient tasks and reduce destructive behaviors [20]. Akers, C analyzed students' emotional evaluation in agricultural science courses, and the results showed that fully and scientifically evaluating students' emotions can promote students' learning motivation [21]. The existing literature indicates that emotional assessment is an important content of emotional management, which is widely used in medicine and psychology. The whole literature also tends to accept that emotional assessment is an important force to strengthen students' self-management and improve their learning motivation and performance level. Therefore, this study puts forward hypothesis $\mathrm{H} 2$.

$\mathrm{H} 2$ : Emotional assessment significantly and positively promotes learners' knowledge construction.

Emotional expression mainly reflects that learners' emotions in the process of online learning are influenced not only by their own learning pressure and motivation but also by the emotions expressed by teachers and classmates who like and hate online learning. The active emotional expression of teachers and classmates helps learners participate in the society and the learning process, and obtaining better learning performance is more likely. With regard to the relationship between emotional expression and learning, Collier, $\mathrm{G}$ believed that emotional expression, as the main content of emotional management, fully understands and analyzes the psychological changes of emotional expression, which is conducive to more accurate analysis of learners' inner motivation [22]. Elliott, D.J. thought that teachers in music education should pay more attention to students' emotional expression in various ways [23], which requires teachers' close attention. Prosen, S studied the role of teachers' emotional expression in classroom in teachers' interaction with students [24]. The results showed that primary school teachers' showing various happy and unhappy emotions will reduce students' enthusiasm for learning. Lee, J analyzed the emotional expression content experienced by students, and the results showed that students using digital visualization technology, language tools, and visual, auditory, and tactile senses can more abundantly feel the teacher's emotional expression, which is helpful to increasing students' learning power [25]. Liu, Y showed that the emotional expression (i.e., emotional masking and emotional sharing) and social activities of interns will affect the extent to which they learn and receive guidance from their supervisors during the internship, which in turn affects interns' job satisfaction and the emotional commitment and professional attitude of the intern sponsor [26]. Prosen, S studied the feedback mechanism of elementary school teachers' emotional expression types to students [27]. The results showed that the students' discipline and academic achievements have caused teachers' happy and unhappy emotions, and the teachers' poor emotional expressions will be fed back to the students. Bonastre, $\mathrm{C}$ believed that teachers' emotional expression in the process of music teaching will affect students' understanding of musical expressiveness [28]. Wang, L argued that customized teaching of emotional expression learners in MOOC learning can help them improve the completion and graduation rates. Therefore, this article proposes hypothesis H3 [29]. 
H3: Emotional expression significantly positively promotes learners' knowledge construction.

The extensive development of Internet teaching has enabled online collaborative learning, including teacher-student collaboration and collaboration among students. Collaborative learning model has become a popular new education and learning model in the global education field. Macdonald, J. evaluated the process and function of online collaborative learning, and the results showed that setting up online collaborative learning between teachers and students effectively improves the level of online learning, which is beneficial to students' knowledge improvement [30]. Thompson, L investigated the online cooperation experience and attitude of 12 graduate students in instructional design courses [31]. The results showed that the quality of the project is better and the attitude toward the project is more active when more teamwork is enacted. In 2012, a questionnaire survey was conducted among freshmen majoring in educational science in Flanders University and Chinese universities [32]. The research showed that online collaboration can improve students' academic performance and realize the knowledge construction of students. Hernández-Sellés showed that online collaborative learning can strengthen the interaction of group students and help improve the interaction and emotional maintenance of team members [33]. Muuro, M. E analyzed the challenges that students perceive in the online collaborative learning environment under the background of Web 2.0. The research showed that online collaborative learning is a convenient teaching mode that enables universities to provide students with high-quality education [34]. Tsai, C. W designed a course and adopted online collaborative learning in the initial stage of the course to establish the basic knowledge of student collaboration [35]. The research results showed that students who accept online collaborative learning that have been initiated have higher grades than those who have not. Therefore, online collaborative learning is important. Saqr, $\mathrm{M}$ found that students have a lot of interactive behaviors in online collaborative discussions. Such interactive collaboration helps them fully understand the social structure of the curriculum and track knowledge flow and interactive patterns [36]. Altınay, $\mathrm{Z}$ evaluated the importance of online peer learning in the collaborative learning process in higher education practice [37]. The results showed that the collaborative online peer learning process in higher education encourages critical reflection and self-evaluation. Zhang, $\mathrm{K}$ investigated the first online collaborative learning experience of 48 undergraduates in a project-based learning environment, and the research results showed that online collaborative learning is important to the application of higher education and to cross-cultural implementation [38]. The existing literature shows that the online collaborative learning environment provides learners with opportunities for practical training and knowledge building with the demand and development of multilevel interaction, resource sharing, and deep learning. Therefore, this study proposes hypothesis $\mathrm{H} 4$.

$\mathrm{H} 4$ : Online collaboration plays a mediating role in the positive promotion of learners' knowledge construction by emotional interaction. 


\section{$3 \quad$ Research design}

\subsection{Questionnaire design}

On the basis of the existing literature scale, this study designed a questionnaire of "Emotional Interaction on Learners' Knowledge Construction in Online Collaboration Mode," which included 25 questions. Among them, the first part is the basic information of the investigated group, including four topics in the basic information part. The second part is the core variable questionnaire, including 4 questions of emotional response, 5 questions of emotional assessment, 4 questions of emotional expression, 4 questions of knowledge construction, and 4 questions of online cooperation mode. In this study, the scale was set in the seven-point form of Likert scale, and the options were set from " 1 " (very different) to " 7 " (very agree).

\subsection{Research objects}

In this study, a questionnaire survey was conducted among undergraduates of a 211 university in Beijing, which is a liberal arts and business type. The university, as a pilot university of online teaching reform in Beijing, has fully conducted online course learning, and approximately $18 \%$ of the courses adopt a blended learning mode. Nearly $14 \%$ of the content of each course requires online mixed teaching by teachers and students, and the course content is studied and discussed through the network platform the rest of the time. In this survey, 246 questionnaires were distributed, and 177 valid questionnaires were finally obtained after eliminating the irregular or incomplete questionnaires, with an effective recovery rate of $71.95 \%$. Descriptive statistical results of specific objects are shown in Table 1.

Table 1. Descriptive statistical results of questionnaire subjects

\begin{tabular}{|l|c|c|c|c|}
\hline \multicolumn{1}{|c|}{ Name } & Option & Frequency & Proportion (\%) & Cumulative proportion (\%) \\
\hline \multirow{4}{*}{ Gender } & Male & 98 & 55.37 & 55.37 \\
\cline { 2 - 5 } & Female & 79 & 44.63 & 100 \\
\hline \multirow{5}{*}{ Grade } & Grade 1 & 57 & 32.20 & 32.20 \\
\cline { 2 - 5 } & Grade 2 & 66 & 37.29 & 69.49 \\
\cline { 2 - 5 } & Grade 3 & 25 & 14.12 & 83.62 \\
\cline { 2 - 5 } & Grade 4 & 29 & 16.38 & 100 \\
\hline \multirow{5}{*}{ Subject } & Philosophy & 22 & 12.43 & 12.43 \\
\cline { 2 - 5 } & Economics & 32 & 18.08 & 30.51 \\
\cline { 2 - 5 } & Law & 69 & 38.98 & 69.49 \\
\cline { 2 - 5 } & Education & 28 & 15.82 & 85.31 \\
\cline { 2 - 5 } & Literature & 19 & 10.73 & 96.05 \\
\cline { 2 - 5 } & History & 7 & 3.950 & 100 \\
\hline \multirow{4}{*}{$\begin{array}{l}\text { Are you willing to accept the } \\
\text { online learning writing mode? }\end{array}$} & No & 58 & 32.77 & 32.77 \\
\cline { 2 - 5 } & Yes & 119 & 67.23 & 100 \\
\hline Total & & 177 & 100 & 100 \\
\hline
\end{tabular}




\section{$4 \quad$ Result analysis}

\subsection{Reliability and validity test}

The reliability of questionnaire test determines to the reliability of questionnaire. Different calculation methods can be divided into different reliability indexes, such as retest reliability and duplicate reliability obtained according to correlation, and internal consistency reliability calculated according to special formula. Cronbach's $\alpha$ coefficient under internal consistency reliability is used as the reliability test index in this study to test the consistency of internal topics. Cronbach's $\alpha$ coefficient is generally greater than 0.7 , which means that the questionnaire has good reliability.

Table 2 shows that the Cronbach's $\alpha$ coefficients of each variable are $0.895,0.821$, $0.832,0.873$, and 0.965 . The Cronbach's $\alpha$ coefficient of the questionnaire is 0.891 , both of which are greater than 0.8 , which indicates that the designed questionnaire designed has good reliability.

Table 2. Reliability test results

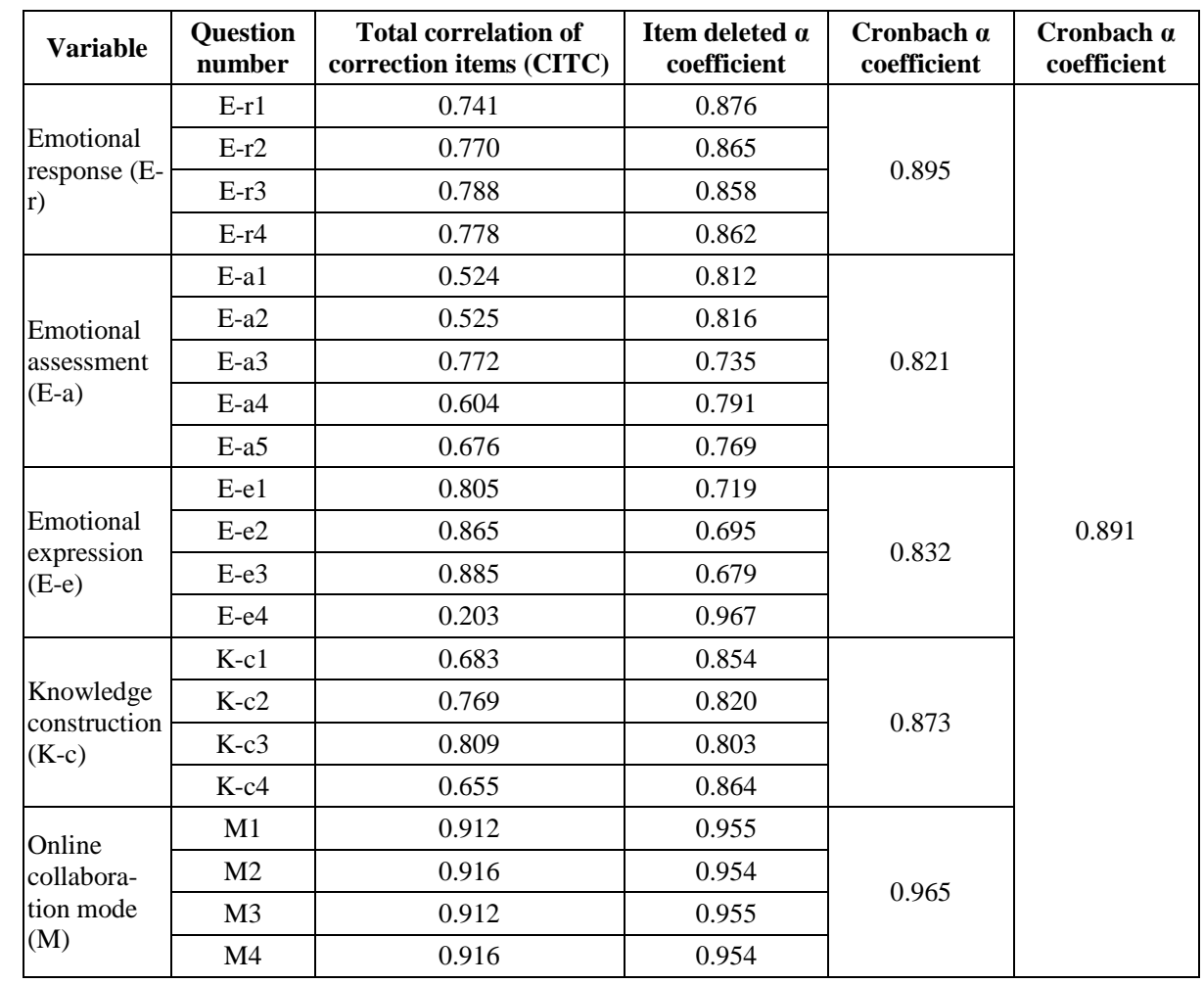

The convergence validity is analyzed, and the average variance extraction value is adopted as the index, that is, the variance interpretation ability of variable is measured. The reliability and convergence validity of the construct are higher when the 
average variance extraction is higher. Discriminant validity analysis method is also the mainstream analysis method at present, and its condition is that the root value of AVE of a dimension is greater than the correlation coefficient of other related dimensions.

Table 3 shows that the KMO value is 0.876 and the corresponding $\mathrm{P}$ value is 0 . Therefore, the validity of this questionnaire is good. At the same time, the AVE and $\mathrm{CR}$ values of the questionnaire are analyzed.

Table 3. Validity analysis results

\begin{tabular}{|c|c|c|c|c|c|c|c|}
\hline \multirow[b]{2}{*}{ Name } & \multicolumn{6}{|c|}{ Factor load factor } & \multirow{2}{*}{$\begin{array}{l}\text { Common degree } \\
\text { (variance of } \\
\text { common factor) }\end{array}$} \\
\hline & $\begin{array}{c}\text { Factor } \\
1\end{array}$ & $\begin{array}{c}\text { Factor } \\
2\end{array}$ & $\begin{array}{c}\text { Factor } \\
3\end{array}$ & $\begin{array}{c}\text { Factor } \\
4\end{array}$ & $\begin{array}{c}\text { Factor } \\
5\end{array}$ & $\begin{array}{c}\text { Factor } \\
6\end{array}$ & \\
\hline E-r1 & 0.206 & 0.241 & 0.275 & 0.684 & 0.058 & 0.031 & 0.648 \\
\hline E-r2 & 0.155 & 0.113 & 0.064 & 0.892 & 0.039 & -0.036 & 0.84 \\
\hline E-r3 & 0.231 & 0.163 & 0.077 & 0.834 & -0.013 & 0.089 & 0.79 \\
\hline E-r4 & 0.33 & 0.217 & 0.093 & 0.772 & 0.086 & 0.176 & 0.799 \\
\hline E-a1 & 0.816 & 0.149 & 0.086 & 0.197 & 0.139 & 0.095 & 0.762 \\
\hline E-a2 & 0.823 & 0.15 & -0.006 & 0.18 & 0.049 & 0.177 & 0.766 \\
\hline E-a3 & 0.846 & 0.225 & 0.066 & 0.171 & 0.123 & -0.043 & 0.817 \\
\hline E-a4 & 0.799 & 0.312 & 0.16 & 0.223 & 0.14 & 0.015 & 0.831 \\
\hline E-a5 & 0.846 & 0.188 & 0.085 & 0.212 & 0.203 & -0.064 & 0.849 \\
\hline E-e1 & 0.133 & 0.163 & 0.215 & 0.058 & 0.918 & 0.08 & 0.943 \\
\hline E-e2 & 0.22 & 0.171 & 0.185 & 0.014 & 0.903 & 0.057 & 0.931 \\
\hline E-e3 & 0.154 & 0.095 & 0.165 & 0.046 & 0.912 & 0.154 & 0.918 \\
\hline E-e4 & 0.132 & 0.168 & 0.245 & 0.207 & 0.388 & 0.81 & 0.956 \\
\hline K-c1 & 0.072 & 0.012 & 0.813 & 0.097 & 0.273 & 0.149 & 0.772 \\
\hline K-c2 & 0.072 & 0.017 & 0.835 & 0.099 & 0.233 & 0.059 & 0.77 \\
\hline K-c3 & 0.034 & 0.089 & 0.915 & 0.108 & 0.061 & 0.012 & 0.861 \\
\hline K-c4 & 0.146 & 0.425 & 0.731 & 0.141 & 0.047 & 0.013 & 0.759 \\
\hline M1 & 0.228 & 0.873 & 0.071 & 0.157 & 0.168 & 0.045 & 0.875 \\
\hline M2 & 0.28 & 0.878 & 0.108 & 0.147 & 0.077 & 0.081 & 0.895 \\
\hline M3 & 0.18 & 0.865 & 0.107 & 0.236 & 0.164 & -0.039 & 0.877 \\
\hline M4 & 0.224 & 0.884 & 0.109 & 0.179 & 0.095 & 0.113 & 0.898 \\
\hline $\begin{array}{l}\text { Root value of feature (before } \\
\text { rotation) }\end{array}$ & 8.701 & 2.939 & 2.062 & 1.887 & 1.38 & 0.589 & - \\
\hline $\begin{array}{l}\text { Explanation rate of variance } \% \\
\text { (before rotation) }\end{array}$ & $\begin{array}{c}41.433 \\
\% \\
\end{array}$ & $\begin{array}{c}13.997 \\
\%\end{array}$ & $9.818 \%$ & $8.985 \%$ & $6.570 \%$ & $2.803 \%$ & - \\
\hline $\begin{array}{l}\text { Cumulative variance explanation } \\
\text { rate } \% \text { (before rotation) }\end{array}$ & $\begin{array}{c}41.433 \\
\%\end{array}$ & $\begin{array}{c}55.430 \\
\%\end{array}$ & $\begin{array}{c}65.248 \\
\%\end{array}$ & $\begin{array}{c}74.233 \\
\%\end{array}$ & $\begin{array}{c}80.804 \\
\%\end{array}$ & $\begin{array}{c}83.606 \\
\%\end{array}$ & - \\
\hline $\begin{array}{l}\text { Root value of feature (after rota- } \\
\text { tion) }\end{array}$ & 3.996 & 3.719 & 3.076 & 2.985 & 2.957 & 0.826 & - \\
\hline $\begin{array}{l}\text { Explanation rate of variance\% } \\
\text { (after rotation) }\end{array}$ & $\begin{array}{c}19.027 \\
\% \\
\end{array}$ & $\begin{array}{c}17.707 \\
\%\end{array}$ & $\begin{array}{c}14.646 \\
\% \\
\end{array}$ & $\begin{array}{c}14.213 \\
\%\end{array}$ & $\begin{array}{c}14.081 \\
\%\end{array}$ & $3.933 \%$ & - \\
\hline $\begin{array}{l}\text { Cumulative variance explanation } \\
\text { rate } \% \text { (after rotation) }\end{array}$ & $\begin{array}{c}19.027 \\
\%\end{array}$ & $\begin{array}{c}36.734 \\
\%\end{array}$ & $\begin{array}{c}51.380 \\
\%\end{array}$ & $\begin{array}{c}65.593 \\
\%\end{array}$ & $\begin{array}{c}79.674 \\
\%\end{array}$ & $\begin{array}{c}83.606 \\
\%\end{array}$ & - \\
\hline
\end{tabular}




\begin{tabular}{|l|c|c|}
\hline KMO value & 0.876 & - \\
\hline Bart sphere value & 3397.979 & - \\
\hline Df & 210 & - \\
\hline p value & 0 & - \\
\hline
\end{tabular}

Table 4 shows that 5 factors and 21 analysis items are used for confirmatory factor analysis (CFA) analysis. The table shows that the AVE values corresponding to the five factors are all greater than 0.5 , and the CR values are all higher than 0.7 . Therefore, the analysis data have good convergence validity.

Table 4. Model AVE and CR indicator results

\begin{tabular}{|l|c|c|}
\hline \multicolumn{1}{|c|}{ Factor } & AVE value of mean variance extraction & Combination reliability CR value \\
\hline E-r & 0.660 & 0.886 \\
\hline E-a & 0.734 & 0.932 \\
\hline E-e & 0.812 & 0.941 \\
\hline K-c & 0.660 & 0.886 \\
\hline M & 0.843 & 0.955 \\
\hline
\end{tabular}

CFA can be used to study discrimination validity. The diagonal line in the table is the square root value of AVE, and other values are correlation coefficients. AVE square root value can indicate the "aggregation" of factors, correlation coefficient indicates correlation, and all factors show such a conclusion, which indicates that it has good discrimination validity. Table 5 shows that the square root value of AVE of five variables is greater than the maximum value of absolute value of correlation coefficient among factors. Therefore, the designed questionnaire has good discrimination validity.

Table 5. Discrimination validity: Pearson correlation and square root value of AVE

\begin{tabular}{|l|c|c|c|c|c|}
\hline & E-r & E-a & E-e & K-c & M \\
\hline E-r & 0.812 & - & - & - & - \\
\hline E-a & 0.523 & 0.857 & - & - & - \\
\hline E-e & 0.253 & 0.386 & 0.901 & - & - \\
\hline K-c & 0.337 & 0.269 & 0.439 & 0.813 & - \\
\hline M & 0.464 & 0.514 & 0.368 & 0.334 & 0.918 \\
\hline
\end{tabular}

\subsection{Regression analysis}

The following results are obtained from Table 6.

Suppose H1 holds. Specifically, emotional response significantly positively promotes the establishment of learners' knowledge construction. In fact, online learning is accepted by students quickly given that it is a new educational model. The research showed that positive emotional response is the basic element of interdependent and cooperative learning. Among them, the teacher-student emotional response of online 
learning task and the emotional response between students can ensure that students can better exchange knowledge and learning experiences, and teachers and students can better communicate with each other in teaching methods and contents. Students have good team spirit, as an important part of learners. They are more inclined to exchange and share learning information in a friendly way. Thus, they can achieve better learning results in their studies. At the same time, the teacher's emotional response can make students feel the teacher's concern for his learning process, improve the satisfaction of students' online collaborative learning, and make their learning efficiency significantly higher.

Suppose $\mathrm{H} 2$ does not hold, that is, emotional assessment cannot significantly and positively promote learners' knowledge construction. This conclusion seems to be inconsistent with the existing research conclusions. The possible reason is that emotion, as a complex factor, may incorrectly reflect students' true learning level if it is simply evaluated from teachers and students. It also inspires our university to pay more attention to the emotional changes of students in the online learning process. Teachers cannot simply put tasks on the online platform without considering students' acceptance of learning tasks and psychological and emotional changes. We should pay attention to the influence of teachers' and classmates' words, behaviors, and expressions on students' online collaborative learning.

Suppose H3 holds, that is, emotional expression significantly promotes learners' knowledge construction. An interaction exists between traditional classroom teachers and students, but many students will not actively interact with teachers in online learning. Therefore, teachers under the online collaborative learning mode will tell students the collaborative learning mode and the importance of collaboration among groups at the beginning of the course. Thus, learners can realize that collaborative learning plays an irreplaceable role in students' knowledge search and building their own knowledge system. This way can fully enable students to conduct emotional expression, build good trust and concern in learners' groups, enhance the collective sense of honor in collaborative learning, and also give feedback to learners that they can express their emotions more fully in the process of collaborative learning. Accordingly, the construction of online learning knowledge is realized.

Table 6. Linear regression results

\begin{tabular}{|c|c|c|c|c|c|c|c|}
\hline & Normalization coefficient & $\mathbf{t}$ & $\mathbf{P}$ & VIF & $\mathbf{R}^{2}$ & Adjust R $\mathbf{R}^{2}$ & $\mathbf{F}$ \\
\hline Constant & - & 4.012 & $0.000^{* *}$ & - & \multirow{4}{*}{0.247} & \multirow{4}{*}{0.234} & \multirow{4}{*}{$\mathrm{F}(3,173)=18.964, \mathrm{p}=0.000$} \\
\hline E-r & 0.244 & 3.146 & $0.002^{* *}$ & 1.383 & & & \\
\hline E-a & -0.005 & -0.063 & 0.95 & 1.522 & & & \\
\hline E-e & 0.379 & 5.294 & $0.000^{* *}$ & 1.18 & & & \\
\hline
\end{tabular}

Dependent variable: K-c

$\mathrm{D}-\mathrm{W}$ value: 1.523

${ }^{*} \mathrm{p}<0.05^{* *} \mathrm{p}<0.01$ 


\subsection{Mediating effect analysis}

Intermediary effect is also called indirect effect. If VariableX acts on VariableY through VariableM, then $M$ is called intermediary Variable. If the effect is significant, then a mediating effect exists between VariableX and VariableY. Bootstrap method is currently the most suitable method to test the mediation effect. It uses replacement sampling for sample sampling, which avoids a series of problems such as data disobedience to normal distribution and formula errors. It is tested by finding the confidence interval of the effect. If the confidence interval does not include 0 , then the mediating effect is significant.

Table 7 shows that $\mathrm{H} 4$ holds, that is, online collaboration plays a complete mediating role in the positive promotion of learners' knowledge construction by emotional interaction. The main reason is that online collaboration mode can make students have a significant impact on learners' attitude and self-efficacy, and it indirectly affects learners' knowledge construction. In the process of collaborative learning, students easily accept the intuitive and convenient features of online learning platform, which improves learners' perceived usefulness of online learning. Thus, it further improves learners' willingness to communicate and share, helps learners logically store the knowledge they need, tracks the records of learners' evaluation and interaction, keeps learning traces, strengthens learners' sense of self-ability, stimulates learning passion, improves learning performance, and realizes learners' knowledge construction.

Table 7. Mediating effect results

\begin{tabular}{|c|c|c|c|}
\hline & K-c & $\mathbf{M}$ & K-c \\
\hline Constant & $2.813^{* *}(6.736)$ & $1.984^{* *}(5.573)$ & $1.828^{* *}(4.439)$ \\
\hline E-a & $0.363^{* *}(4.212)$ & $0.547^{* *}(7.444)$ & $0.091(1.017)$ \\
\hline $\mathrm{M}$ & & & $0.497^{* *}(6.164)$ \\
\hline Sample size & 177 & 177 & 177 \\
\hline $\mathrm{R}^{2}$ & 0.092 & 0.241 & 0.255 \\
\hline Adjust R² & 0.087 & 0.236 & 0.246 \\
\hline F value & $F(1,175)=17.739, p=0.000$ & $\mathrm{~F}(1,175)=55.419, \mathrm{p}=0.000$ & $F(2,174)=29.740, p=0.000$ \\
\hline
\end{tabular}

\subsection{T test and variance analysis}

In this study, t-test is used to study the differences of two types of data (whether they are willing to accept online learning writing mode and gender) in knowledge construction. Table 8 shows that whether you are willing to accept the online learning collaboration mode is significant for the average score of the questionnaire of knowledge construction Variable $(\mathrm{p}<0.05)$. The average of willingness to accept online learning collaboration mode (5.14) is significantly higher than that of unwillingness to accept online learning collaboration mode (4.67). Gender will not produce significant differences in knowledge construction because the students of this 985 university will not affect gender differences in their knowledge construction regardless of their male and female information literacy. 
Table 8. T test results

\begin{tabular}{|c|c|c|c|c|}
\hline & \multicolumn{2}{|c|}{$\begin{array}{l}\text { Are you willing to accept the online learning collaboration model (mean } \pm \\
\text { standard deviation) }\end{array}$} & \multirow[t]{2}{*}{$\mathbf{t}$} & \multirow[t]{2}{*}{$\mathbf{p}$} \\
\hline & No $(\mathrm{n}=58)$ & Yes $(n=119)$ & & \\
\hline \multirow[t]{3}{*}{ K-c } & $4.67 \pm 1.23$ & $5.14 \pm 1.04$ & 2.495 & $0.014 *$ \\
\hline & \multicolumn{2}{|c|}{ Gender (mean \pm standard deviation $)$} & \multirow{2}{*}{$\mathrm{t}$} & \multirow{2}{*}{$\mathrm{p}$} \\
\hline & Male $(n=98)$ & Female $(\mathrm{n}=79)$ & & \\
\hline K-c & $4.78 \pm 1.16$ & $4.88 \pm 1.23$ & -0.597 & 0.551 \\
\hline
\end{tabular}

Analysis of variance (one-way analysis of variance) is used to study the differences in knowledge construction by grades and disciplines. Table 9 shows that samples of different grades are all significant for knowledge construction $(\mathrm{p}<0.05)$, which means samples of different grades have differences in knowledge construction. Judging from the knowledge construction scores of the grades, the third grade has the highest score, the second grade is the second, and the first and fourth grades are the last. Given that undergraduates are studying for four years, the junior is particularly critical. Juniors are more accepting of online learning after the freshman and sophomore stages. Thus, they have a significant role in promoting their knowledge construction. Freshmen have only entered students from high school. Thus, they do not have a high degree of acceptance of students' self-study. Seniors spend more time on internships and employment. Thus, their love for online collaborative learning between teachers and students is very low, which leads to their low scores for knowledge construction. Thus, universities focus on online learning for seniors when they leave school. Collaboration, cooperation, and communication with teachers will improve the knowledge construction level of seniors. Samples from different disciplines are insignificant for knowledge construction ( $p>0.05$ ). This finding shows that the online collaborative learning policies of the universities surveyed in this study are relatively balanced in different branches and disciplines, and different levels of knowledge construction caused by discipline differences are not observed. Therefore, the online learning education policy of the university is in different disciplines.

Table 9. Variance test results

\begin{tabular}{|c|c|c|c|c|c|c|c|c|}
\hline & \multicolumn{4}{|c|}{ Grade (mean \pm standard deviation) } & \multirow{2}{*}{\multicolumn{2}{|c|}{$\mathbf{F}$}} & \multirow{2}{*}{\multicolumn{2}{|c|}{$\mathbf{p}$}} \\
\hline & $\begin{array}{c}1.0 \\
(n=57)\end{array}$ & $\begin{array}{c}2.0 \\
(n=66)\end{array}$ & $\begin{array}{c}3.0 \\
(n=25)\end{array}$ & $\begin{array}{c}4.0 \\
(n=29)\end{array}$ & & & & \\
\hline \multirow[t]{3}{*}{ K-c } & $4.82 \pm 1.06$ & $5.14 \pm 0.97$ & $5.21 \pm 1.68$ & $3.78 \pm 0.72$ & \multicolumn{2}{|c|}{11.856} & \multicolumn{2}{|c|}{$0.000^{* *}$} \\
\hline & \multicolumn{6}{|c|}{ Subject (mean \pm standard deviation) } & \multirow{2}{*}{$\mathrm{F}$} & \multirow{2}{*}{$\mathrm{p}$} \\
\hline & $1.0(n=22)$ & $2.0(n=32)$ & $3.0(n=69)$ & $4.0(n=28)$ & $5.0(n=19)$ & $6.0(n=7)$ & & \\
\hline K-c & $4.81 \pm 1.19$ & $4.92 \pm 1.09$ & $4.71 \pm 1.17$ & $4.96 \pm 1.37$ & $4.83 \pm 1.24$ & $4.96 \pm 1.23$ & 0.263 & 0.933 \\
\hline
\end{tabular}




\section{Conclusions}

Information and communication technologies, such as online resources, online technologies, and multimedia, have brought revolutionary changes to traditional teaching methods, learning, and life. Learning is conducted with the help of network technology and abundant online resources to meet people's needs for learning anytime, anywhere, across time, and space. This study designs a questionnaire on the knowledge construction of learners by emotional interaction in the online collaboration mode. The mechanism of the three factors of emotional interaction on the knowledge construction of learners is analyzed. The mediation of online collaboration in the construction of learners' knowledge by emotional interaction is verified. The research results show that the Cronbach's $\alpha$ coefficient of the designed questionnaire is 0.891 , which is greater than 0.8 . Therefore, the questionnaire has good reliability. The KMO value is 0.876 , and the corresponding $\mathrm{P}$ value is 0 . Therefore, the questionnaire has good validity. Emotional response and emotional expression significantly positively promote the establishment of learners' knowledge construction. Online collaboration plays a complete mediating effect in emotional interaction, which promotes the construction of learners' knowledge. Whether students are willing to accept the online learning collaboration model and grades have significant differences in knowledge construction. Comprehensively investigating the application degree of emotional interaction in the process of online collaborative learning, constructing the connotation index system of emotional interaction, and determining the influence of learner's personal characteristics in online collaborative learning on organizational collaborative learning performance are interesting future research directions.

\section{Acknowledgement}

The study was supported by the Humanities and social science research projects of education department of Henan province (Project No.: 2021-ZDJH-0423).

\section{$7 \quad$ References}

[1] Fredrickson, B. L. (2001). The role of positive emotions in positive psychology: the broaden-and-build theory of positive emotions. American psychologist, 2001, vol. 56(3), pp. 218. https://doi.org/10.1037/0003-066x.56.3.218

[2] Bodner, G. M. (1986). Constructivism: A theory of knowledge. Journal of chemical education, 1986, vol. 63(10), pp. 873.

[3] McPhail, K. (2004). An emotional response to the state of accounting education: developing accounting students' emotional intelligence. Critical perspectives on Accounting, 2004, vol. 15(4-5), pp. 629-648. https://doi.org/10.1016/s1045-2354(03)00050-9

[4] Litvack, A., Mishna, F., \& Bogo, M. (2010). Emotional reactions of students in field education: An exploratory study. Journal of Social Work Education, 2010, vol. 46(2), pp. 227243. https://doi.org/10.5175/jswe.2010.200900007 
[5] Egan, K. Young Children's Imagination and Learning: Engaging Children's Emotional Response. Young Children, 1994, vol. 49(6), pp. 27-32.

[6] Madsen, C. K. Emotional response to music as measured by the two-dimensional CRDI. Journal of Music Therapy, 1997, vol. 34(3), pp. 187-199. https://doi.org/10.1093/ $\mathrm{imt} / 34.3 .187$

[7] Gfeller, K., Asmus, E., \& Eckert, M. An investigation of emotional response to music and text. Psychology of Music, 1991, vol. 19(2), pp. 128-141. https://doi.org/10.1177/ 0305735691192004

[8] Bibby, T. Shame: An emotional response to doing mathematics as an adult and a teacher. British Educational Research Journal, 2002, vol. 28(5), pp. 705-721. https://doi.org/ 10.1080/0141192022000015543

[9] Kim, E. J., \& Lee, K. R. Effects of an examiner's positive and negative feedback on selfassessment of skill performance, emotional response, and self-efficacy in Korea: a quasiexperimental study. BMC medical education, 2019, vol. 19(1), pp. 1-7. https://doi.org/10. 1186/s12909-019-1595-X

[10] Mottet, T. P., \& Beebe, S. A. Relationships between teacher nonverbal immediacy, student emotional response, and perceived student learning. Communication Research Reports, 2002, vol. 19(1), pp. 77-88. https://doi.org/10.1080/08824090209384834

[11] Brooks, R. Social and spatial disparities in emotional responses to education: feelings of 'guilt'among student- parents. British Educational Research Journal, 2015, vol. 41(3), pp. 505-519. https://doi.org/10.1002/berj.3154

[12] Horan, S. M., Martin, M. M., \& Weber, K. Understanding emotional response theory: The role of instructor power and justice messages. Communication Quarterly, 212, vol. 60(2), pp. 210-233. https://doi.org/10.1080/01463373.2012.669323

[13] Woody, R. H., \& Burns, K. J. Predicting music appreciation with past emotional responses to music. Journal of Research in Music Education, 2001, vol. 49(1), pp. 57-70. https://doi.org/10.2307/3345810

[14] Randler, C., Ilg, A., \& Kern, J. Cognitive and emotional evaluation of an amphibian conservation program for elementary school students. The Journal of Environmental Education, 2005, vol. 37(1), pp. 43-52. https://doi.org/10.3200/joee.37.1.43-52

[15] Brandtstadter, J., Krampen, G., \& Greve, W. Personal control over development: Effects on the perception and emotional evaluation of personal development in adulthood. International Journal of Behavioral Development, 1987, vol. 10(1), pp. 99-120. https://doi.org/10. $1177 / 016502548701000107$

[16] Fox, P., \& Avramidis, E. An evaluation of an outdoor education programme for students with emotional and behavioural difficulties. Emotional and Behavioural Difficulties, 2003, vol. 8(4), pp. 267-283. https://doi.org/10.1080/13632750300507025

[17] Merrell, K. W., Juskelis, M. P., Tran, O. K., \& Buchanan, R. Social and emotional learning in the classroom: Evaluation of strong kids and strong teens on students' social-emotional knowledge and symptoms. Journal of applied school psychology, 2008, vol. 24(2), pp. 209-224. https://doi.org/10.1080/15377900802089981

[18] Ioannou, A. A model of gameful design for learning using interactive tabletops: enactment and evaluation in the socio-emotional education classroom. Educational Technology Research and Development, 2019, vol. 67(2), pp. 277-302. https://doi.org/10.1007/s11423018-9610-1

[19] Gutiérrez-Moret, M., Ibáñez-Martinez, R., Aguilar-Moya, R., \& Vidal-Infer, A. Assessment of emotional intelligence in a sample of prospective secondary education teachers. Journal of Education for Teaching, 2016, vol. 42(2), pp. 123-134. https://doi.org/10.1080/ $\underline{02607476.2016 .1143144}$ 
[20] Kamps, D., Wendland, M., \& Culpepper, M. Active teacher participation in functional behavior assessment for students with emotional and behavioral disorders risks in general education classrooms. Behavioral Disorders, 2006, vol. 31(2), pp. 128-146. https://doi.org/ $\underline{10.1177 / 019874290603100203}$

[21] Akers, C., Miller, K., Fraze, S. D., \& Haygood, J. D. A tri-state needs assessment of emotional intelligence in agricultural education. Journal of agricultural Education, 2004, vol. 45(1), pp. 86-94. https://doi.org/10.5032/jae.2004.01086

[22] Collier, G., \& Collier, G. J. Emotional expression. Psychology Press, 2014.

[23] Elliott, D. J. Musical understanding, musical works, and emotional expression: Implications for education. Educational Philosophy and Theory, 2005, vol. 37(1), pp. 93-103. https://doi.org/10.1111/j.1469-5812.2005.00100.x

[24] Prosen, S., Smrtnik Vitulic, H., \& Poljsak Skraban, O. Teachers' emotional expression in interaction with students of different ages. CEPS journal, 2011, vol. 1(3), pp. 141-157. https://doi.org/10.26529/cepsi.419

[25] Lee, J., \& Lee, S. S. Research on the emotional expression of synesthesia through STEAM Education Program. The Journal of the Korea Contents Association, 2013, vol. 13(9), pp. 448-454. https://doi.org/10.5392/jkca.2013.13.09.448

[26] Liu, Y., Xu, J., \& Weitz, B. A. The role of emotional expression and mentoring in internship learning. Academy of Management Learning \& Education, 2011, vol. 10(1), pp. 94110. https://doi.org/10.5465/amle.10.1.zqr94

[27] Prosen, S., Smrtnik Vitulić, H., \& Poljšak-Škraban, O. Observing teachers' emotional expression in their interaction with students. The new educational review, 2013, vol. 31(1), pp. 75-85.

[28] Bonastre, C., \& Timmers, R. Comparison of beliefs about teaching and learning of emotional expression in music performance between Spanish and English HE students of music. Psychology of Music, 2021, vol. 49(1), pp. 108-123. https://doi.org/10.1177/03057 $\underline{35619842366}$

[29] Wang, L., Hu, G., \& Zhou, T. Semantic analysis of learners' emotional tendencies on online MOOC education. Sustainability, 2018, vol. 10(6), pp. 1921. https://doi.org/10. 3390/su10061921

[30] Macdonald, J. Assessing online collaborative learning: process and product. Computers \& education, 2003, vol. 40(4), pp. 377-391. https://doi.org/10.1016/s0360-1315(02)00168-9

[31] Thompson, L., \& Ku, H. Y. A case study of online collaborative learning. Quarterly Review of Distance Education, 2006, vol. 7(4), pp. 361.

[32] Zhu, C. Student satisfaction, performance, and knowledge construction in online collaborative learning. Journal of Educational Technology \& Society, 212, vol. 15(1), pp. 127136.

[33] Hernández-Sellés, N., Muñoz-Carril, P. C., \& González-Sanmamed, M. Computersupported collaborative learning: An analysis of the relationship between interaction, emotional support and online collaborative tools. Computers \& Education, 2019, vol. 138, pp. 1-12. https://doi.org/10.1016/j.compedu.2019.04.012

[34] Muuro, M. E., Wagacha, W. P., Kihoro, J., \& Oboko, R. Students' perceived challenges in an online collaborative learning environment: A case of higher learning institutions in Nairobi, Kenya. International Review of Research in Open and Distributed Learning, 2014, vol. 15(6), pp. 132-161. https://doi.org/10.19173/irrodl.v15i6.1768

[35] Tsai, C. W. Do students need teacher's initiation in online collaborative learning? Computers \& Education, 2010, vol. 54(4), pp. 1137-1144. https://doi.org/10.1016/ j.compedu.2009.10.021 
Paper-Influence of Emotional Interaction on Learners' Knowledge Construction in Online Collaboration...

[36] Saqr, M., Fors, U., \& Tedre, M. How the study of online collaborative learning can guide teachers and predict students' performance in a medical course. BMC medical education, 2018, vol. 18(1), pp. 1-14. https://doi.org/10.1186/s12909-018-1126-1

[37] Altınay, Z. Evaluating peer learning and assessment in online collaborative learning environments. Behaviour \& Information Technology, 2017, vol. 36(3), pp. 312-320. https://doi.org/10.1080/0144929x.2016.1232752

[38] Zhang, K., Peng, S. W., \& Hung, J. L. Online collaborative learning in a project- based learning environment in Taiwan: a case study on undergraduate students' perspectives. Educational Media International, 2009, vol. 46(2), pp. 123-135. https://doi.org/10.1080/ $\underline{09523980902933425}$

\section{Author}

Liqin Wen is a Lecturer in Zhengzhou University of Light Industry, Zhengzhou, Henan, 450002, China.

Article submitted 2021-11-01. Resubmitted 2021-12-10. Final acceptance 2021-12-11. Final version published as submitted by the author. 